\title{
OPTIMUM DESIGN BASIS \\ OF DIGGING EQUIPMENT OF EARTH MOVING MACHINES \\ ON EXAMPLE OF A BACKHOE ATTACHMENT
}

\author{
Dr. Eugeniusz BUDNY \\ Institute of Building Mechanization and Rock Mining, WARSAW
}

\section{SUMMARY}

A method of optimization in the design of earth moving equipment is presented in this paper, using the example of a backhoe digging equipment. Its working capacity has been described with the use of geometric concepts deriving from the mechanics of a discrete set of points. Expressions depicting the magnitude and shape of a hodograph of potential digging forces have been taken as the objective function. A computer implementation of the presented method has also been developed in form of STAKOP system of calculations supporting equipment design.

Keywords: CAD, attachment, excavator

\section{INTRODUCTION}

Work has been conducted in the Institute of Building Mechanization and Rock Mining in Warsaw, to develop computer assisted design of working attachments to earth moving machinery. Backhoe attachments belong to the most complex equipment in this category. The reason to start this work was a view that the methods of designing used at present are not effective (cf references [1], [2], [4] and [5]), and that the equipment designed by employing these methods is far from being optimal. What is essential in the design of this equipment is the interdependence between its geometry and strength parameters on one hand, and the working capacity of the whole machine on the other. As may be inferred from the analysis of literature available, the equipment design problem used to be approached by numerous authors fragmentarily. Such an approach, in view of the necessity of a multi-criterial analysis of a function of many variables, makes the optimization problem a relatively complex and slowly convergent one. The method suggested by the present author allows to construct a suitable, discrete mathematical model of equipment, forming an accurate, tensor representation of all essential phenomena occurring during operation, including among others the geometry, statics and kinematics of the system.

The purpose of this paper is to introduce the Reader to the analysis of equipment geometry and statics, and to the optimization of digging forces in the machine working area. A STAKOP computer software developed from this research is now available in the Institute. It is used in formulating and solving various optimization problems of working equipment analysis and design.

The following initial assumptions have been made:

1) components connected by articulated joints are regarded as rigid bodies, and the number of segments (degrees of freedom) is unlimited,

2) friction forces in equipment joints are ignored as negligibly 
3) the potential capacity of the equipment and basic machine are analyzed without regard for the physical/mechanical properties of soil,

4. the programme takes account of dynamic effects of acceleration of masses, neglecting impact and vibrations.

The third from the above assumptions is in conformity with general practice in design, where the type of soil for a considered machine is usually assumed leaving out the ground faults, intrusions or offsets. It seems, as a consequence that the quality of equipment is decided by the largest digging forces it is able to transmit. This ability is named "loading capacity" in what follows [3].

A discret mathematical model of equipment has been chosen for this analysis, allowing to make use of such concepts as base, metric, vector field and a parallel transfer of vector in a flat metric space. The machine digging attachment is replaced by a lattice structure, with nodes representing the attachment characteristic points (articulated and other joints, points of force application etc.). All external forces, such as forces in hydraulic cylinders, reactions, gravity and digging forces are concentrated at the lattice nodes (Fig. 1). As it appears, the discrete point model of equipment does not introduce any errors into the statics (i.e. forces calculated using this model are the same as the ones taking account of mass being distributed continuously). Since the force distribution depends on attachment configuration in the working area which in turn is a function of extension of hydraulic cylinders, the analysis has been carried out with cylinder stroke divided into $\eta_{\mathrm{k}}$ equal parts. Consequently, the working area is divided into $n^{k}$ different configurations (testing points), where:

$\mathrm{k}$ - number of hydraulic cylinders in the attachment.

other notation used in this paper:

$\xi$ - number of lattice model segment on a parametric line;

$\mathrm{R}_{A}, \mathrm{R}_{B}$ - normal reactions of supports of basic machine;

$R_{s t}$ - tangential reaction of supports of basic machine;

$\tau_{i}$ - force in hydraulic cylinder $i$;

$K$ - vector of digging force;

$\mathbb{K}$ - configuration (one of the $n^{\mathrm{k}}$ possible);

9 - equipment geometry (set of numbers defining equipment component dimensions);

$\rho \mathrm{M}$ - distribution of mass in equipment;

$\mathrm{H}_{1}$ - part of digging forces hodograph, essential for practical reasons (Fig. 2);

$\mathrm{S}(\overline{\mathrm{x}})$ - surface area of flat set $\mathrm{H}_{1}$;

$\mathrm{L}(\overline{\mathrm{x}})$ - circumference of flat set $\mathrm{H}_{1}$;

$d$ - controlling parameter, $d \in<1,2)$;

opc - user options, e.g. a fourth hydraulic cylinder;

w - equipment operation mechanism;

$\mathrm{T}$ - set of utilized hydraulic cylinders in equipment control.

2. EQUIPMENT WORKING AREA, STATICS, KINEMATICS AND LOADING CAPACITY

Working area is defined as a flat metric surface enclosed by the nath of the excavators bucket edoe for al o possible equinment 
configuration.

Both the arm and bucket are usually employed during a digging operation. There is also a combination of these two movements, as a possibility. The force applied to the end of bucket blade, balancing the forces of active cylinders and the reactions of ground will be called a digging force $\mathrm{K}$. There is no possibility of universal determination of the magnitude and direction of the ground reaction on the bucket, due to variation of ground properties and it's non-uniformity.

The analysis of excavators statics during operation yields a system of three equations relating 5 unknowns, in the form:

$$
\begin{aligned}
& F_{v} \cdot x_{C}+F_{H} \cdot Y_{C}+R_{B} \cdot x_{B}-\sum M_{A G}=0 \\
& R_{H}-F_{H}=0 \\
& R_{A}+R_{A}+F_{A}-\Sigma G=0
\end{aligned}
$$

one of the limitations in digging force value is the loss of stability by rotation about support $A$. In this instance $R_{B} \leq 0$ and eq. (1) assumes the form:

$$
F_{v} \cdot x_{C}+F_{H} \cdot y_{C}-\sum M_{A G} \geq 0
$$

The above inequality is defining a half-plane containing the digging force vector, whereas a straight line described by the equation

$\mathrm{F}_{\mathrm{V}} \cdot \mathrm{x}_{\mathrm{C}}+\mathrm{F}_{\mathrm{H}} \cdot \mathrm{y}_{\mathrm{C}}-\mathrm{EM}_{\mathrm{AG}}=0$

is called a hodograph of the limit digging force causing the loss of stability by rotation about support $A$. Other limitations associated with rotation about support B, excavator slip, limited pressure, etc. can be defined analogously. As a result, a hodograph of limit forces is obtained, named a hodograph of potential digging forces. The actual digging force vector is contained inside this polygon and may be of any direction, sense and value (Fig. 2). Within the hodograph one may distinguish a zone of forces concurrent with the normal direction of equipment effort, with the vector of actual digging force usually inside the zone.

The loading capacity of an excavator is the maximum loads generated during operation, which are statically permissible for the machine to carry. The term has been borrowed from the theory of limit load capacity for rigid/plastic bodies. The instance of stability loss due to forces in hydraulic cylinders being exceeded is the analogon of plastic flow in the original theory. By developing the equipment weight into characteristic points of the multisegmental model and by writing down equilibrium equations about points $5,4,3$ and 1 , a set of seven linear equations with nine unknowns may be written to describe the backhoe excavator statics. The set in matrix form is as follows: 


$$
\left[\begin{array}{ccccccccc}
a_{11} & 0 & a_{13} & 0 & 0 & 0 & 0 & 0 & 0 \\
0 & 0 & a_{23} & a_{24} & 0 & 0 & 0 & 0 & 0 \\
a_{31} & a_{32} & 0 & 0 & a_{35} & 0 & 0 & 0 & 0 \\
a_{41} & a_{42} & 0 & 0 & 0 & a_{46} & 0 & 0 & 0 \\
a_{51} & a_{52} & 0 & 0 & 0 & 0 & 0 & a_{58} & 0 \\
a_{61} & a_{62} & 0 & 0 & 0 & 0 & a_{67} & a_{68} & 0 \\
a_{1} & a_{1} & 0 & 0 & 0 & 0 & 0 & 0 & 1
\end{array}\right] \cdot\left[\begin{array}{c}
s \\
n \\
\tau_{4} \\
\tau_{3} \\
\tau_{2} \\
\tau_{1} \\
R_{A} \\
R_{B} \\
R_{s t}
\end{array}\right]=\left[\begin{array}{c}
b_{1} \\
b_{2} \\
b_{3} \\
b_{4} \\
b_{5} \\
b_{6} \\
b_{7}
\end{array}\right]
$$

It follows that by using equipment geometry to describe the location of all equipment nodal points (joints), one obtains a set of linear equations of matrix $A(\mathbb{K}, g, w)$, which is dependent on configuration, geometry, and mechanism of operation. The vector of the right-hand sides $b(\mathbb{K}, g, \rho M)$ is dependent on configuration, geometry and mass distribution.

$A x=b$

where:

$$
\text { vector } x=\left[s, n, \tau_{k}, \ldots, \tau_{2}, \tau_{1}, R_{A}, R_{B}, R_{s t}\right]^{T}
$$

is the vector of unknown forces.

Two additional equations should be arbitrarily imposed in order to solve the above set. Here it will be the equations defining forces in the two hydraulic cylinders of the arm and bucket, as the maximum ones (determined by the by-pass valve setting). Such an additional assumption will be called the selection of mechanism of operation $w$. What is important as a conclusion for further analysis, resulting from the linearity of set (7), is the existence of a certain set $S$ in the space of digging forces, which is contained within the hodograph of potential digging forces $\mathrm{H}_{\mathrm{W}}(\mathbb{K})$. The latter is a locus of all digging forces which do not cause the loss of excavator stability or forces beyond permissible in hydraulic cylinders. The set in question is a convex polygon (a hexagon at most).

As boundary conditions of the equations of statics one will have only those external forces, which cause the digging force to remain inside the hodograph of potential digging forces (see Fig. 2). While considering the set $S$ for different configurations it may be inferred that equipment geometry. That the usability and operational properties of not only the attachment but also of the entire excavator unit may be almost fully described by the equipment geometry, its variation and the singularities of the set $S$. For example the surface area and shape of set $S$ (say, close to a semi-circle) could constitute useful parameters in the machine evaluation, and could render themselves for optimization (see Fig. 3). 
full working capacity is not reached in some configurations. In this case, the digging force will cross the boundary of hodograph $\mathrm{H}_{\mathrm{W}}(\mathrm{g})$ if maximum allowable forces are applied at some of the hydraulic cylinders.

This cannot happen in actual operation, since it would cause the loss of excavator stability, or else the activation of cylinder safety valves. It means that the set of equations (6) and (7) becomes useless as far as examination of the distribution of internal forces on the equipment individual components is concerned. The following hypothesis is introduced in order to solve this problem:

The actual digging force $\mathrm{K}^{*}$ (constituting one of boundary conditions in equipment internal forces calculation) is such that its vector is a vector fully contained in hodograph $\mathrm{H}_{\mathrm{W}}(g)$, closest to the vector calculated from set of equations (7) in the meaning of Euclidean metric. Fig. 3 includes an illustration of this hypothesis.

The hypothesis is effected mathematically as a solution of the optimization problem:

$$
\begin{aligned}
\left(K_{10}^{*}-K_{1}\right)^{2}+\left(K_{20}^{*}-K_{2}\right)^{2} & \left.=\min _{\left[K_{1}^{*}, K_{2}^{*}\right] \in H_{W}(g)}\left(K_{1}^{*}-K_{1}\right)^{2}+\left(K_{2}^{*}-K_{2}\right)^{2}\right\}
\end{aligned}
$$

A calculation of force $K_{0}^{*}$ is followed by computation of forces and stresses in the equipment, with the use of STAKOP software. In addition, dynamic correction are calculated for static forces, resulting from acceleration of masses concentrated at nodes of the multi-segment model [3].

It may be shown that regarding individual units of the attachment as triangles, the correction for inertia forces is:

$F=F^{*}-\frac{1}{6} \cdot M \cdot\left(b^{2}+h^{2} \cdot \sin ^{-2} \alpha-b \cdot h \cdot \operatorname{ctg} \alpha\right) \cdot \frac{d}{d \bar{t}}(\bar{\omega})$

where: $F^{*}$ - load calculated from set (7) and (8);

M - total mass of equipment units;

$b, h$, and $\alpha$ - dimensions of a triangle, substituted for equipment units;

$\bar{\omega}$ - vector of angular velocity of equipment units.

In conclusion one may state, that a two-dimensional mechanical system composed of triangular plates may represented by a lattice discrete segmental model.

\section{OPTIMIZATION OF ATTACHMENTS}

As mentioned in the introduction, the purpose of this research was develop a professional computer software for analysis of equipment parameters as formulation and solving of optimization problems in earth moving attachments design. It was assumed for the STAKOP programme, that the data defining the dimensions of the bucket and linked are established. Other parameters describing the geometry of the multisegmental model (12) are variables, subject to optimization (Fig. 1). Additional constraints have also been imposed, requiring the resulting equipment working area to always 
appropriate height of discharge to be preserved. Both of these limitations are effected through the mechanism of penalty function, allowing to reject those sets of data which cause irregularities.

It is assumed that initial data are determined by the following magnitudes:

M - total mass of excavators with attachment;

$\mathrm{h}_{0}$ - height of the highest point of working area over ground level;

$a_{0} \quad-$ distance between excavators axis of rotation and working area;

$A B C D_{0}$ - trapezoid describing the part of working area where digging forces are practically important.

An illustration of these magnitudes is offered in Fig. 4. We may note, that from practical viewpoint only the digging forces occurring when the bucket is being filled is important. Hence, if $s$ denotes a vector tangent to bucket path, the part of hodograph where $s \cdot K$ product has negative value is of no importance. Therefore, it is worthwhile to introduce an auxiliary concept of an effective hodograph of forces $\mathrm{H}_{1}$.

$\mathrm{H}_{1}(\mathrm{~g})=\mathrm{H}_{\mathrm{W}}(\mathrm{g}) \cap\{\mathrm{K}: \mathrm{K} \cdot \mathrm{s} \geq 0\}$

Before moving on to objective function, another definition should be introduced of a certain subset of all possible configurations of equipment geometry $G$. It is obvious that the height of discharge $h$, distance $a$, as well as the relation of trapezoid $A B C D$ being contained in the equipment working area P ef' $^{\prime}$ are functions of equipment geometry $g$. The subset $G$ is defined by the equation:

$G=\left\{g: h_{0} \leq h(g) ; a_{0}=a(g) ; A B C D \subset P(g)\right\}$

Using the above notation, the objective function takes the following form:

$F(g, \rho M, \tau$, opc $)=S^{-1}\left(P_{\text {ef }}\right) \cdot{\underset{P}{\text { ef }}}_{\int} S\left(H_{1}(\mathbb{K})\right) \cdot L^{-d}\left(H_{1}(\mathbb{K})\right)=$

$=\frac{\sum_{j} S\left(H_{1}(K)\right) \cdot L^{-d}\left(H_{f}(K)\right)}{S\left(P_{e f}\right)}$

This is a mean value of function

$$
f(g, \rho M, \tau, o p c)=S\left(H_{1}\right) \cdot L^{-d}\left(H_{1}\right)
$$

on set $\mathrm{P}_{\text {ef }}$, which is the most important part of working area from the viewpoint of digging. Integrand $f$ is the ratio of the surface area of the essential part of forces hodograph $H_{1}$ to its 
Hence, the larger the length $L$, the more flattered the $\mathrm{H}_{1}$ part of hodograph becomes. Parameter d has been introduce to enable balancing of the proportion between the numerator and denominator of the objective function. Three examples of hodograph $\mathrm{H}_{1}$ are shown in Fig. 5. Among them example a) should be regarded as most desirable, because a relatively large digging force is obtained for a wide range of directions. Example b) carries a threat of loss of stability, whereas in example c) a too small digging force parallel to the direction of bucket tip movement was assumed.

Finally, the optimization problem for backhoe excavator may be mathematically described in the following manner:

To find such

$\mathrm{n}_{0} \in\{3,4\}, \tau_{0} \in \mathrm{T}, \mathrm{g}_{0} \in \mathrm{G}$, and $\rho_{0} \mathrm{M}$ such that $\sum \rho_{0} \mathrm{M}=\mathrm{M}$,

that

$\mathrm{F}\left(g_{0}, \rho_{0} \mathrm{M}, \tau_{0}, \mathrm{n}_{0}\right)=\max \mathrm{F}(\mathrm{g}, \rho \mathrm{M}, \tau, \mathrm{n})$

on conditions that

$g \in \mathrm{G}, \tau \in \mathrm{T}, \mathrm{n} \in\{3,4\}, \sum \rho \mathrm{M}=\mathrm{M}$.

one should also notice that function $F$ is complicated algorithm relating the equipment geometric parameters to a desirable distribution of forces in the effective excavator working area.

Rosenbrock method has been employed in solving of the optimization problem, because the objective function is not known explicitly, and that in may include discontinuities. In order to satisfy the constraints $h$ and $P_{\text {ef' }}$ a penalty function has been brought in, with its zero value for all decision vectors not meeting the constrains.

The calculation programme STAKOP takes, in source form, a total of over $400 \mathrm{kB}$ and about 15000 code lines, meaning over 200 pages of listing. The system has reached, at present, the level of professional software. It allows a designer to effectively employ it in equipment design, even without any special training in information technology.

\section{REFERENCES}

[1] Brach I.: Jednonaczyniowe koparki hydrauliczne, WNT, Warszawa 1970 .

[2] Frackiewicz H.: Mechanika osrodkow siatkowych, PWN, Warszawa 1970 .

[3] Budny E.: Mechanika osprzetow roboczych koparek hydraulicznych jednonaczyniowych, IMB, Warszawa 1984.

[4] Röhrs W, van Hamme Th.: Hydrauliksysteme in standardbaggern, Baumaschinen und Technik, No. 7/1987, page 315.

[5] Timoshenko V. K: Raschot racionalnyh paramietrov strielopodiemnovo mechanizma gidravlicheskovo ekskavatora. Stroitielnyie $i$ dorojnyie mashiny, No. 3/1986.

[6] Willard I. Zangwill: Programowanie nieliniowe, WNT, Warszawa 1974. 


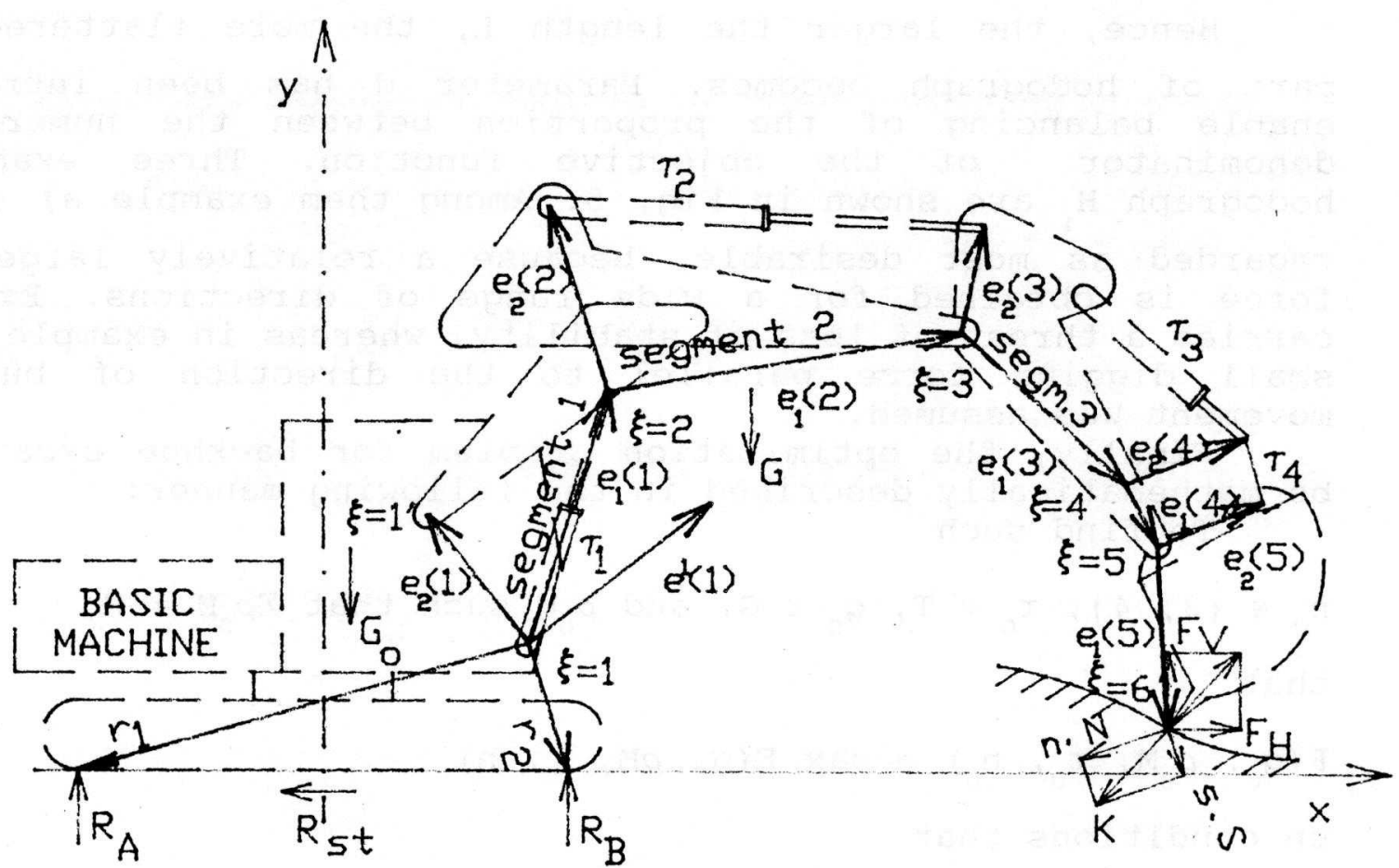

Fig. 1. Backhoe static diagram and multisegmental model of working attachment structure.

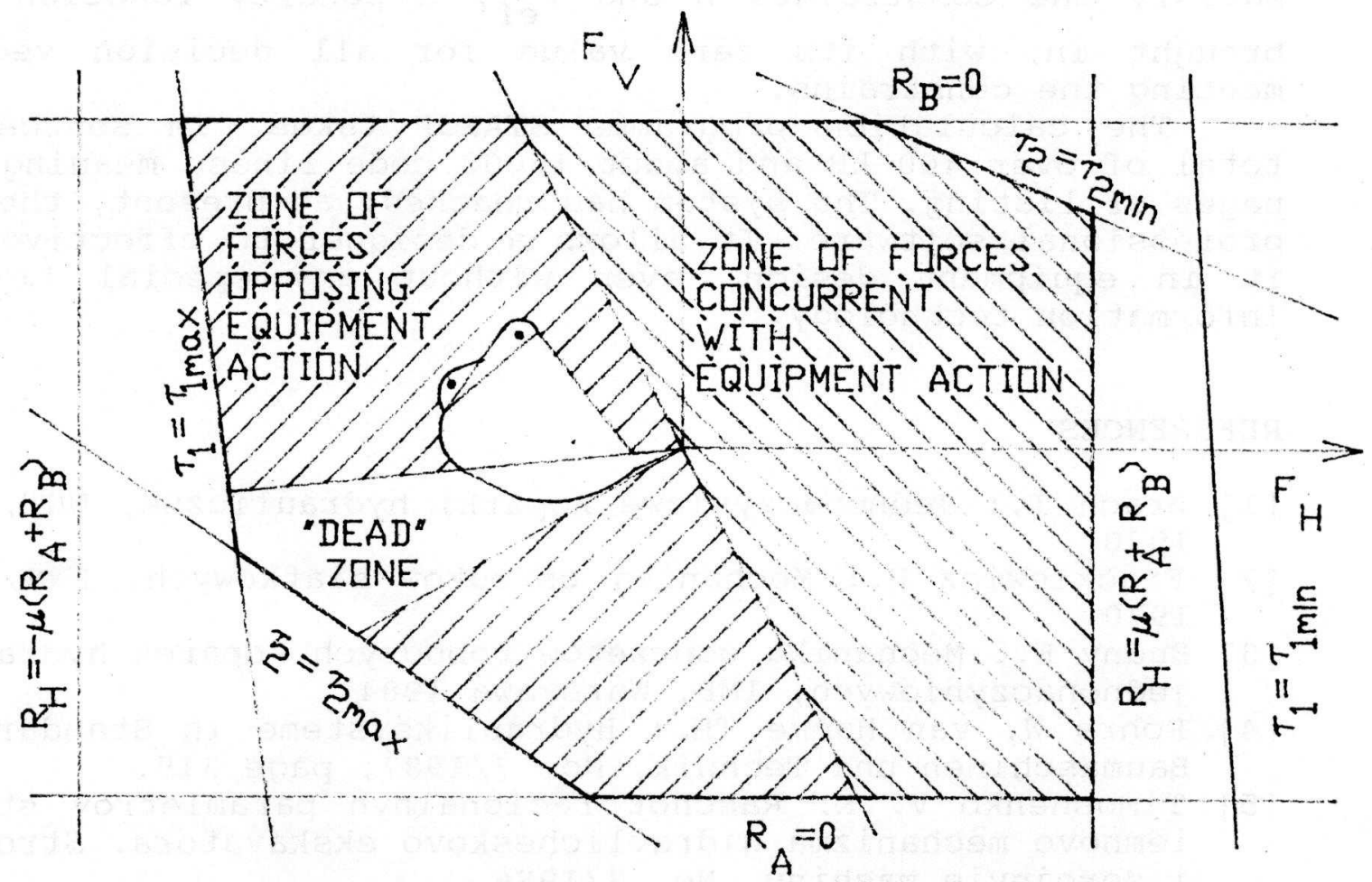

Fig. 2. Hodograph of potential diqging forces. 


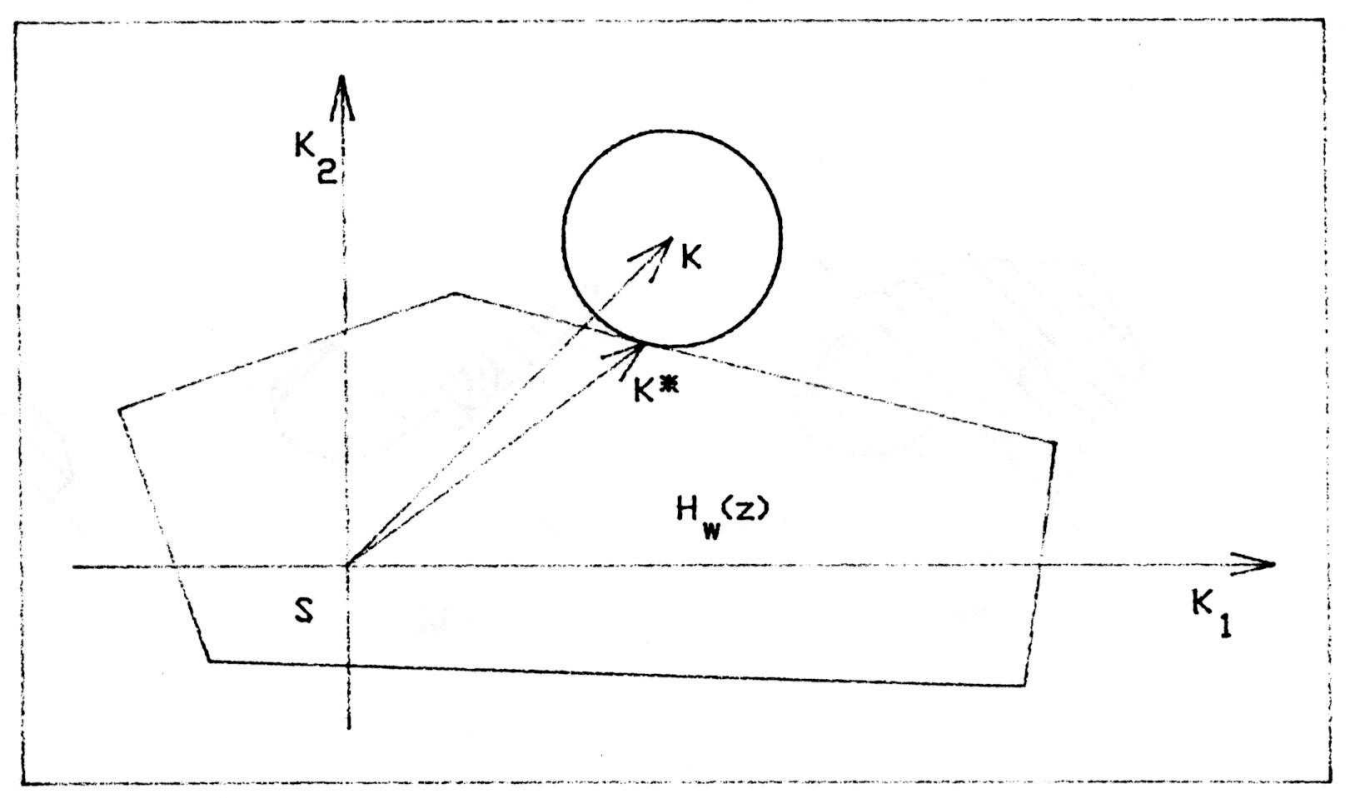

Fig. 3. Finding the actual forces distribution closest to the actually allowable one.

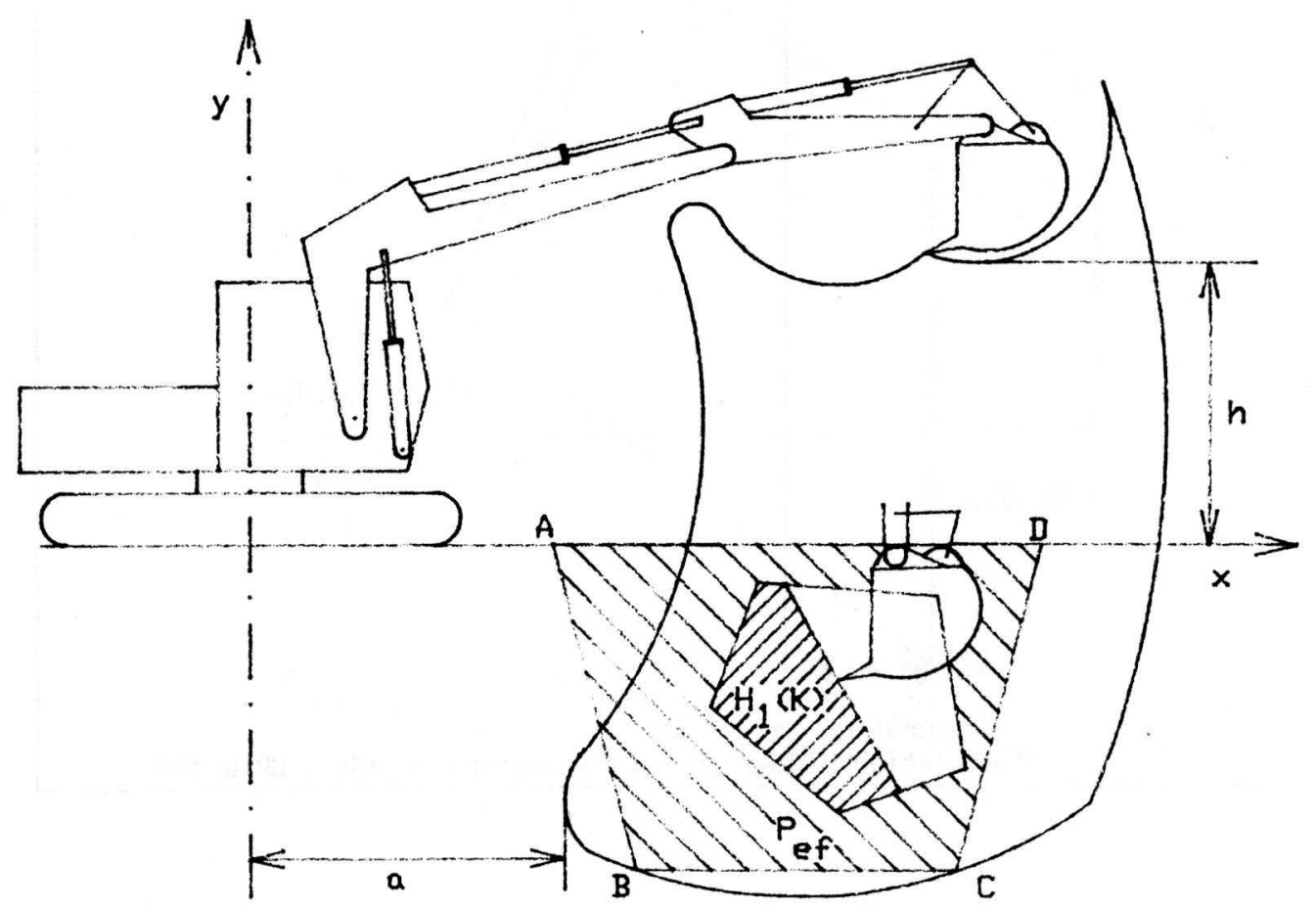

Fig. 4. Working area $P$ showing the optimization parameters $h, a$, 


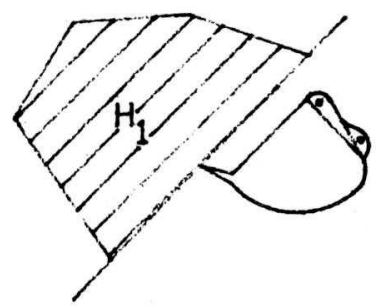

a)

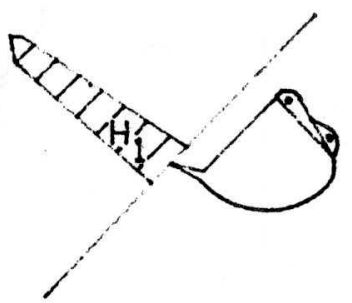

b)

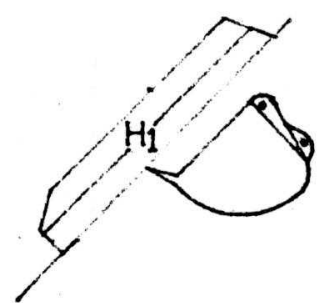

c)

Fig. 5. Various possible shapes of the hodograph of potential forces.

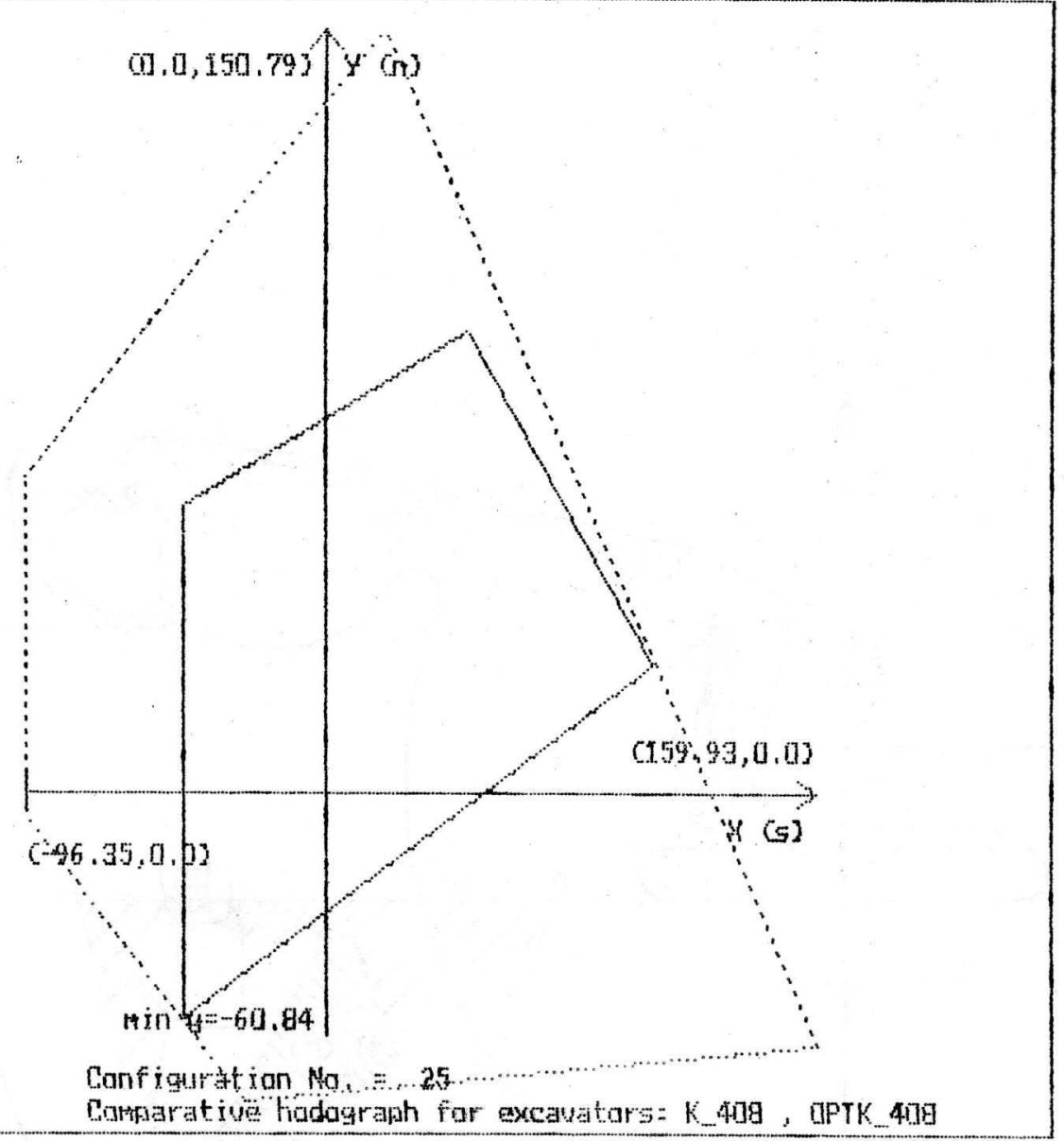

Fig. 6. An example of optimization of forces in the working area of K 408 backhoe excavator (OPTK - after optimization - 